Relato de Caso

CASE REPORT

\title{
Edema Agudo Hemorrágico da Infância ${ }^{(*)}$
}

\section{Acute Hemorrhagic Edema of Infancy}

\author{
Fabiana Britto Goulart ${ }^{(1)}$, Kelma de Sá Torres Lage ${ }^{(2)}$, Maria Vitória Quintero ${ }^{(3)}$ e Paulo Madureira de Pádua ${ }^{(4)}$
}

\section{RESUMO}

Relatamos o caso de uma criança de oito meses de idade com infecção das vias aéreas superiores, seguida de irritabilidade e pelo aparecimento de lesões purpúricas na face, extremidades e pavilhões auriculares e edema de dorso dos pés e das mãos. Inicialmente recebeu dexametasona, ampicilina e cloranfenicol para tratamento de suposta meningococcemia. Entretanto, as lesões características e a boa evolução clínica do quadro levaram-nos ao diagnóstico de uma forma rara de vasculite cutânea: edema agudo hemorrágico da infância.

Palavras-chave: edema agudo hemorrágico da infância, vasculite cutânea, púrpura de Henoch-Schonlein.

\section{INTRODUÇÃO}

Edema agudo hemorrágico da infância é uma vasculite cutânea rara, que acomete crianças entre 5 e 24 meses de idade e usualmente tem curso benigno. A nosologia foi descrita inicialmente por Snow em 1913, nomeada por Finkelstein em 1938 e existem aproximadamente 100 casos descritos. Inicialmente foi melhor reconhecida pela literatura européia. Acredita-se que exista subdiagnóstico e muitos autores defendem tratar-se de um tipo de manifestação da púrpura de Henoch-Schonlein em lactentes $^{(1-3)}$.

A incidência é maior no inverno, com discreta predileção pelo sexo masculino ${ }^{(1,4)}$. A etiopatogenia ainda não está esclarecida, podendo tratar-se de processo imuno-mediado.

\section{ABSTRACT}

We report the case of an eight-month child with upper airway infection followed by irritability and purpuric lesions in his face, ears and extremities and peripheral soft tissue edema. He was treated with dexamethasone, ampicillin and chloramphenicol for presumed meningococcemia, but the characteristics lesions and the benign course of the disease led us to the diagnosis of a rare form of cutaneous vasculitis called Acute Hemorrhagic Edema of Infancy (AHEI).

Keywords: Acute Hemorrhagic Edema of Infancy (AHEI), cutaneous vasculitis, Henoch-Schonlein Purpura.

Em 75\% dos casos há relato de uma infecção recente, uso de medicamentos ou história de imunização ${ }^{(1,4,5)}$.

O quadro clínico compreende irritabilidade, febre baixa e aparecimento súbito e progressivo de lesões purpúricas em face, extremidades, tronco superior e orelhas. As lesões atingem até cinco centímetros de diâmetro assumindo forma arredondada com bordas bem definidas, semelhantes a um medalhão. O prurido não é comum e precocemente surge um edema subjacente e doloroso, que pode ser assimétrico e é observado principalmente em dorso de mãos e pés, couro cabeludo e bolsa escrotal. Algumas lesões podem apresentar áreas de necrose, especialmente aquelas localizadas em pavilhões auriculares ${ }^{(1,4,5,6)}$.

\footnotetext{
* Clínica reumatológica da Santa Casa de Belo Horizonte. Recebido em 24/08/2002. Aprovado, após revisão, em 09/02/2004.

1. Pediatra e Reumatologista, ex-especializanda do segundo ano da clínica reumatológica da Santa Casa de Belo Horizonte.

2. Reumatologista ex-especializanda da clínica reumatológica da Santa Casa de Belo Horizonte.

3. Preceptora do curso de especialização da Santa Casa de Belo Horizonte e responsável pelo setor de Reumatologia Pediátrica.

4. Preceptor e coordenador da clínica reumatológica da Santa Casa de Belo Horizonte, professor titular de Reumatologia da Faculdade de Medicina da Universidade Federal de Minas Gerais.

Endereço para correspondência: Fabiana Britto Goulart. R. Grão Pará 926, ap. 1001, Funcionários, CEP 30150-341, Belo Horizonte, MG, e-mail: fbrittogoulart@bol.com.br
} 


\section{RELATO DE CASO}

MBM, oito meses, masculino, natural e procedente de Belo Horizonte - MG, apresentava história de lesões arroxeadas de aparecimento súbito em membros inferiores, que surgiram uma semana após quadro gripal tratado com dipirona. Não havia relato de febre ou outros sintomas exceto irritabilidade.

História familiar e pregressa sem dados relevantes. Ao exame físico apresentava-se irritado, choroso, hipocorado, subfebril $\left(37,4^{\circ} \mathrm{C}\right)$, hidratado, com boa perfusão capilar e pulsos cheios, taquicárdico $(\mathrm{FC}=140 \mathrm{bpm})$, sem sopros, ausculta respiratória com roncos difusos e abdome sem visceromegalias. Havia edema de dorso dos pés e a criança assumia posição antálgica dos membros inferiores onde se evidenciavam lesões anulares de tamanhos variados, purpúricas, palpáveis e que não desapareciam à vitropressão (Figuras 1 e 2). As maiores tinham até dois centímetros de diâmetro e todas apresentavam desenho vascular central e com bordas bem definidas sem confluência.

A investigação laboratorial evidenciou: hemograma com anemia microcítica e hipocrômica e leucocitose sem desvio (Hb: $9,1 \mathrm{~g} / \mathrm{dl}$, Htc: $29 \%$, GL: $16.900 / \mathrm{mm}^{3}$ com diferencial normal e plaquetas: $163.000 / \mathrm{mm}^{3}$ ), VHS: $65 \mathrm{~mm} / 60 \mathrm{mi}-$ nutos e proteína C reativa: negativa, funções renal e hepática normais, coagulograma normal, rotinas de urina e líquor sem alterações, FAN e látex negativos, C3, C4, IgA e IgG normais, sorologias para Epstein-Barr, citomegalovírus, herpes simples e hepatites negativas, culturas de sangue, urina e líquor negativas.

O paciente recebeu nas primeiras 24 horas ampicilina e cloranfenicol e dose única de dexametasona para tratamento de suposta meningococcemia, ainda sem sinais de choque. Inicialmente não cursou com progressão importante das lesões e manteve ótimo estado geral. No segundo dia de evolução houve disseminação das lesões para membros superiores e pavilhão auricular com regressão concomitante nos membros inferiores, embora persistisse edema em dorso dos pés. Após três dias, as lesões podiam também ser vistas na face com necrose de pavilhão auricular acompanhada de edema significativo. Optou-se pelo início da prednisona $(2 \mathrm{mg} / \mathrm{kg} / \mathrm{dia})$, que não impediu o surgimento de novas lesões sendo algumas em alvo, com centro mais claro (Figura 3). Após 11 dias do início da doença já não havia lesões ativas nem cicatriciais. A criança recebeu alta sem medicações e está em remissão clínica e laboratorial há dois anos.

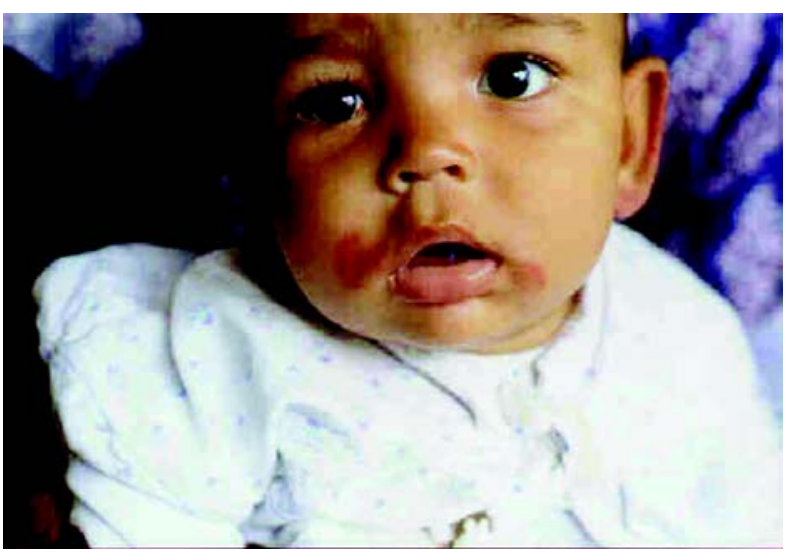

FiguRa 1 - Presença de lesões periorais anulares, purpúricas com bordas bem definidas. Pequena lesão eritematosa em conjuntiva de olho direito.

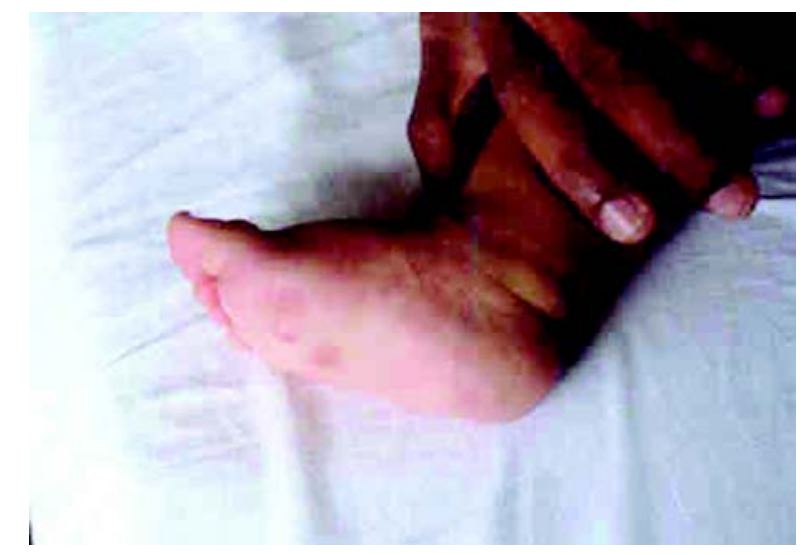

FIgURA 2 - Lesões eritematosas e anulares em dorso e planta com presença de edema em dorso do pé.

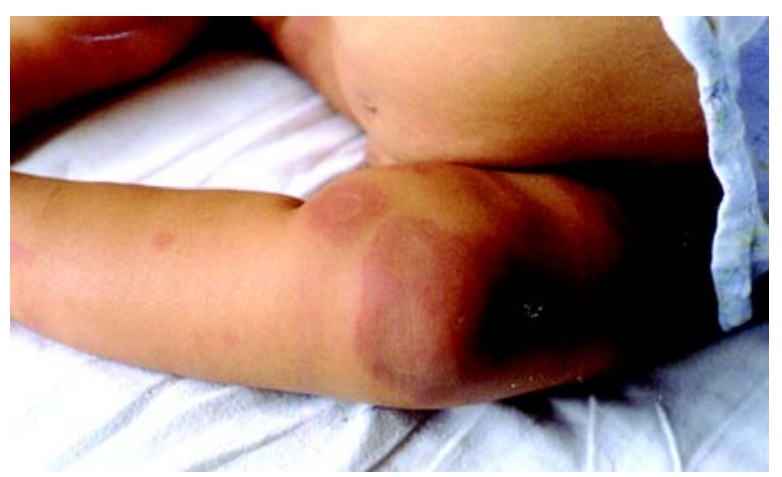

FIguRA 3 - Placas purpúricas, anulares com bordas bem definidas localizadas em membros inferiores com centro mais claro (lesões em alvo). Observar edema subjacente. 


\section{DISCUSSÃO}

Edema agudo hemorrágico de infância (EAHI) é uma vasculite cutânea com evolução benigna que acomete lactentes. A incidência aumenta nos meses de inverno juntamente com as infecções das vias aéreas superiores, que na maioria das vezes precedem o aparecimento das lesões. O uso de medicamentos e/ou imunização também são fatores precipitantes ${ }^{(1-5)}$.

A característica marcante da patologia é o aspecto da lesão, semelhante a um medalhão: placas purpúricas anulares, bordas bem definidas com desenho vascular central localizadas em face e extremidades. Irritabilidade e febre baixa também fazem parte do quadro. As lesões atingem até cinco centímetros de diâmetro, não são pruriginosas e precocemente surge edema subjacente e doloroso observado principalmente nos pés, mãos, couro cabeludo e bolsa escrotal. Algumas podem apresentar áreas de necrose, principalmente aquelas localizadas em pavilhões auriculares. Há contraste entre o importante acometimento cutâneo e o bom estado geral da criança $a^{(2,4,7,8)}$.

Pode haver envolvimento de mucosas; o comprometimento sistêmico é raro, assim como a recorrência dos sintomas ${ }^{(5,7)}$. Os achados laboratoriais são inespecíficos e não ocorre aumento de IgA sérica. Ocasionalmente há leucocitose discreta e eosinofilia; as provas de atividade inflamatória variam de normais a alteradas ${ }^{(2,5)}$. Devem ser obtidas culturas, pois existem relatos de associação com graves infecções ${ }^{(6)}$. Os demais exames (coagulograma, sedimento urinário, função renal e hepática, ASO, IgA e IgM, FAN, VDRL) são normais ${ }^{(1)}$.

O diagnóstico é primariamente clínico. Os achados histopatológicos são de uma vasculite leucocitoclástica com acometimento de pequenos vasos da derme raramente se

\section{REFERÊNCIAS}

1. Saraclar YDM, Tinaztepe KDM, Adalioglu G DM, Tuncer ADM: Acute hemorrhagic edema of infancy (AHEI) - a variant of Henoch Shönlein purpura or a distinct clinical entity? J Allergy Clin Immunol 86: 473-83, 1990.

2. Legrain V DM, Lejean S DM, Taïeb A DM, Guillard JM DM, Battin J DM, Maleville J DM: Infantile acute hemorrhagic edema of skin: study of ten cases. J Am Acad Dermatol 24: 17-22, 1991.

3. Scaramuzza A, Pezzarossa E, Lupi A, Zambelloni C, Lazzari GB, Rossoni R: Case of month: A girl with oedema and purpuric eruption. Eur J Pediatr 156: 813-5, 1997. estendendo ao subcutâneo, necrose fibrinóide, extravasamento de hemácias e edema intersticial. A imunofluorescência direta (IFD) revela depósitos de C3, fibrinogênio e IgM; IgA, IgG e IgE podem ser observados com freqüência bem menor ${ }^{(1,4)}$. Apenas medidas suportivas, como hidratação adequada e controle da temperatura são necessárias ${ }^{(9)}$. $\mathrm{Na}$ maioria das vezes os pacientes recebem o tratamento inicial para um processo infeccioso, embora não haja modificação do quadro clínico; após dez a treze dias já não existem lesões.

Alguns autores defendem tratar-se de uma variante da púrpura de Henoch-Schonlein (PHS), sendo a distribuição das lesões dependente da gravidade (localizadas em tronco e face nos lactentes e membros inferiores nos pré-escolares e escolares) ${ }^{(3)}$. Entretanto, existem diferenças importantes entre as duas patologias ${ }^{(2)}$. a PHS acomete crianças entre três e sete anos, as lesões são principalmente papulopetequiais localizadas em membros inferiores e raramente apresentam edema subjacente. O envolvimento sistêmico é mais comum na PHS (dois terços dos pacientes apresentam manifestações gastrointestinais e articulares, $20 \%$ a $100 \%$ cursam com acometimento renal) e possui duração média de 30 dias e recidivas freqüentes (ocorrendo em até 50\% dos casos $)^{(10,11)}$. Histologicamente, raramente ocorre necrose fibrinóide e a IFD revela depósitos de $\operatorname{IgA}{ }^{(1,4,11,12)}$.

Outros importantes diagnósticos diferenciais do EAHI: lúpus neonatal, meningococcemia, síndrome de Sweet, eritema multiforme, doença de Gianotti e doença de Kawasaki ${ }^{(2,3,4,7)}$.

O reconhecimento da patologia e de sua evolução favorável permite o diagnóstico precoce e uma abordagem mais objetiva, evitando preocupação e tratamentos desnecessários ${ }^{(4)}$.

4. Krause I, Lazarov A, Rachmel A, et al: Acute haemorrhagic oedema of infancy, a benign variant of leucocytoclastic vasculitis. Acta Paediatr 85: 114-7, 1996.

5. Crowe MA MC, Jonas PP MC: Acute hemorrhagic edema of infancy. Cutis 62: 65-6, 1998.

6. Morrison RR DM, Saulsbury FT DM: Acute hemorrhagic edema of infancy associated with pneumococcal bacteremia. Pediatr Infec Dis J 18: 832-3, 1999.

7. Long D DM, Helm KF DM: Acute hemorrhagic edema of infancy: Finkelstein's disease. Cutis 61: 283-4, 1998. 
8. Caliskan S, Tasdan Y, Kasapçopur O, Sever L, Tunnessen WW: Acute hemorrhagic edema of infancy. Arch Pediatr Adolesc Med 149: 1267-8, 1995.

9. Lantner RR, Ros SP: Acute hemorrhagic edema of infancy. Pediatr Emerg Care 12: 111-2, 1996.

10. Oliveira SKF, Azevedo ECL: Reumatologia Pediátrica 2.a ed, Rio de Janeiro, Editora Revinter, 2001.
11. Silva CAA, Campos LMMA, Liphaus BL, Kiss MHB: Púrpura de Henoch - Schönlein na criança e adolescente. Rev Bras Reumatol 40: 128-36, 2000.

12. Tizard EJ: Henoch- Shönlein purpura.Arch Dis Child 80: 380-3, 1999. 